\title{
The ifs, ands, and buts of the dilated aorta
}

\author{
Joseph A. Dearani, MD, and Alberto Pochettino, MD
}

\author{
From the Department of Cardiovascular Surgery, Mayo Clinic, Rochester, Minn. \\ Disclosures: Authors have nothing to disclose with regard to commercial support. \\ Received for publication Dec 21, 2016; accepted for publication Dec 27, 2016; available ahead of print March 11, \\ 2017. \\ Address for reprints: Joseph A. Dearani, MD, Department of Cardiovascular Surgery, Mayo Clinic, 200 First St \\ SW, Rochester, MN 55905 (E-mail: jdearani@mayo.edu). \\ J Thorac Cardiovasc Surg 2017;154:205-6 \\ 0022-5223/ $\$ 36.00$ \\ Copyright $(2017$ by The American Association for Thoracic Surgery \\ http://dx.doi.org/10.1016/j.jtcvs.2016.12.069
}

\section{WHEN TO OPERATE...IF}

Guidelines, algorithms, and protocols have been well documented in the literature and are summarized in the review by Vricella. ${ }^{1}$ Well-established guidelines exist for which aortic sizes should mandate intervention in acquired and genetically driven aortopathies. The group of aortic conditions that remains the most debated is congenital anomalies. ${ }^{2}$ Conotruncal defects are the most common (ie, tetralogy of Fallot, pulmonary atresia, transposition of the great arteries, truncus arteriosus). Aortic dilatation is common and the need for reoperation for right-sided lesions or other abnormalities (ie, pulmonary valve/conduit deterioration, atrioventricular valve regurgitation, residual/recurrent septal defects, and arrhythmias) is common and prompts many phone consultations for advice and guidance about best management of the dilated aorta during the course of a complex reoperation.

The challenges with this class of lesions include the rare occurrence of rupture/dissection despite relatively large ascending aortic diameters, the frequent need for concomitant procedures to be performed, and the presence of multiple prior operations. Furthermore, aortic valve function is frequently preserved in these patients in the face of markedly dilated aortic annulus and sinuses. The literature has shown that surgery involving the dilated ascending aorta at the time of reoperation for other lesions is an independent risk factor for early mortality in adult congenital heart disease. ${ }^{3}$ These issues have rightly resulted in a much higher threshold to intervene on such dilated ascending aorta.

The other common group of anomalies in this "congenital" category includes reoperation after the Ross procedure and to a lesser extent the Norwood procedure. Specific challenges related to the Ross procedure include the potentially high number of prior operations and the need for concomitant procedures beyond the aortic root and ascending aorta (eg, pulmonary valve, atrioventricular valve, arrhythmia). In addition, the dilated proximal aorta or the proximal right coronary artery can be immediately behind the sternum, resulting in a hazardous resternotomy. The dilated aorta in the setting of the Norwood procedure is particularly challenging due to the frequent need for deep hypothermia

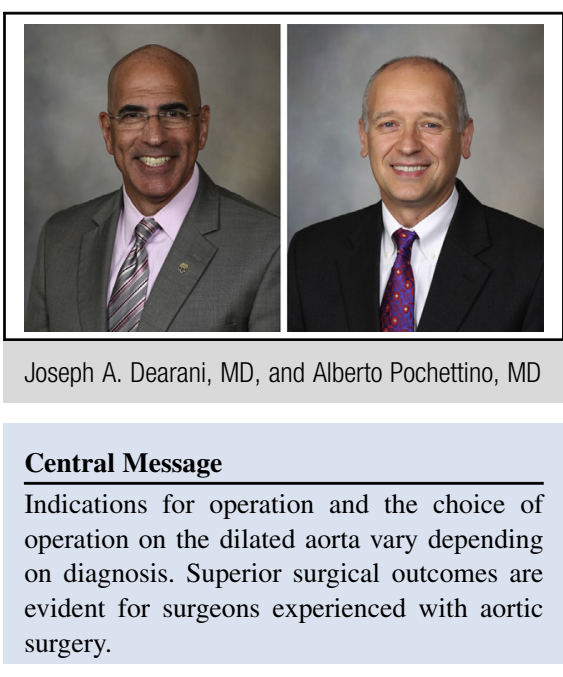

See Article page 207.

and circulatory arrest, difficult myocardial protection secondary to anatomical variants (access to native aortic root, coronary ostia, or coronary sinus) and the overall large magnitude of the procedure in the setting of a single (morphologic right) ventricle circulation. Advanced 3-dimensional imaging (virtual and printed models) can facilitate preparation and planning of the reoperation and optimize outcome.

\section{WHAT OPERATION...AND}

The choice of operation is also determined by the diagnostic category. In general, the valve-sparing root replacement is preferred when aortic valve function is normal ( $\leq$ mild aortic regurgitation). When aortic regurgitation is moderate to severe, or the aortic valve is bicuspid, the decision to preserve the aortic valve is more controversial. The Bentall procedure (composite graft with coronary reimplantation) with either mechanical or tissue valve has been the gold standard for combined aortic root and valve disease. The decision to remove or retain the aortic sinuses is more controversial in the bicuspid aortic valve and congenital groups. In the congenital arena, the specific challenge is the fact that aortic valve function is often normal despite a rather dilated annulus $(34-40 \mathrm{~mm})$, with native leaflets matching well to the dilated annulus. Because the risk of rupture/dissection is very low, most surgeons (and patients) prefer retention of the aortic sinuses and native aortic valve as opposed to aortic root replacement either with a technically challenging valve-sparing root replacement replacement, or with a biological, or mechanical valved conduit. 
In addition, moderate aortic regurgitation in this congenital setting is often amendable to aortic valve repair (commissuroplasty) with better expected long-term results than in the setting of acquired aortic regurgitation, presumably because of the stability of the enlarged annulus. Repair techniques should be strongly considered, particularly if the prosthesis choice for replacement is biologic. Ascending aortic replacement can be very difficult in the setting of a right ventricle-to-pulmonary artery conduit, which is typically densely adherent (and sometimes anterior) to the dilated aorta. Finally, vascular collateralization is common in this group of patients who were initially cyanotic, resulting in more bleeding from the dissection and the systemic hypothermia required to reduce flows to facilitate visualization. All of this leads to a potentially lengthy procedure and the need for transfusion that further increases the risk of surgery. ${ }^{4}$ The importance of a careful and thoughtful operative plan cannot be overemphasized.

\section{WHO SHOULD PERFORM SURGERY ...BUT}

Isolated ascending and aortic arch procedures can be performed at relatively low risk under elective circumstances. However, the risk of these procedures when performed urgently, in the setting of congenital heart disease, or in the setting of multiple concomitant procedures can carry considerable risk, particularly when performed by surgeons with limited experience. ${ }^{5}$ Improvements in cannulation strategies, techniques of resternotomy, and adjunctive techniques for cerebral protection have continued to evolve and are quite familiar to experienced adult and congenital cardiac surgeons. The decision as to who is best suited to perform the procedure must take into account the areas of specific expertise of each surgeon. For example, the adult aortic surgeon may have excellent expertise in cerebral protection strategies, whereas the congenital surgeon may have specific expertise in hazardous sternal reentry with conduit or aortic erosion into the sternum. The collective wisdom and experience of both aortic and congenital surgeons and the importance of discussion and collaboration, a "uniting of forces," in advance of surgery to optimize preparation or actually performing the procedure together will result in the best operation for any given patient.

\section{References}

1. Vricella LA. Nonsyndromic proximal aortic aneurysms: What size matters? Ann Thorac Surg. 2017; 154:207-9.

2. Stulak J, Dearani JA, Burkhart HM, Sundt TM, Connolly HM, Schaff HV. Does the dilated ascending aorta in an adult with congenital heart disease require intervention? J Thorac Cardiovasc Surg. 2010;140:S52-7.

3. Kogon B, Grudziak J, Sahu A, Jokhadar M, McConnell M, Book W, et al. Surgery in adults with congenital heart disease: risk factors for morbidity and mortality. Ann Thorac Surg. 2013;95:1377-84.

4. Holst KA, Dearani JA, Burkhart HM, Connolly HM, Warnes CA, Li Z, et al. Risk factors and early outcome of multiple reoperations in adults with congenital heart disease. Ann Thorac Surg. 2011;92:122-30.

5. Lenos A, Bougioukakis P, Irimie V, Zacher M, Diegeler A, Urbanski PP. Impact of surgical experience on outcome in surgery of acute type A aortic dissection. Eur J Cardiothorac Surg. 2015;48:491-6. 